\title{
Native forest replacement changes fruit geometry on Tristerix corymbosus (Loranthaceae), a keystone mistletoe
}

\section{El reemplazo del bosque nativo cambia la geometría de los frutos de Tristerix corymbosus, un quintral clave}

\author{
Francisco E. Fontúrbel ${ }^{1 *}$ \& Alina B. Candia ${ }^{2}$ \\ ${ }^{1}$ Instituto de Biología, Facultad de Ciencias, Pontificia Universidad Católica de Valparaíso, Valparaíso, Chile. \\ ${ }^{2}$ Departamento de Ciencias Ecológicas, Facultad de Ciencias, Universidad de Chile, Santiago, Chile. \\ *fonturbel@gmail.com
}

\begin{abstract}
RESUMEN
Las condiciones microclimáticas pueden alterar rasgos en las plantas, como la geometría del fruto, que es importante para las interacciones planta-frugívoro. Mediante morfometría geométrica se examinó el efecto del reemplazo del bosque sobre la forma de los frutos de Tristerix corymbosus, cuya forma cambió significativamente de alargada a redondeada.
\end{abstract}

Land use change caused by anthropogenic activities is a major driver of biological change (Chapin III et al. 2000, Sala et al. 2000). In this sense, forest plantations cover 187 million ha worldwide (Brown 2001) and usually their establishment result from the replacement of preexisting native forests (Echeverría et al. 2006, Newbold et al. 2015) by monocultures of fast-growing exotic trees (mainly Pinus spp. and Eucalyptus spp.). Productive lands (either active or abandoned) can hold a subset of generalist / tolerant species (Peh et al. 2006), usually favored by the presence of native understory vegetation (Nájera \& Simonetti 2009, Fontúrbel et al. 2016). Even when some species are able to persist after forest replacement, major structural and functional changes alter the ecological scenario in which those species and their interactions thrive (Stockwell et al. 2003, Kinnison et al. 2007).

Among those species thriving on degraded lands, we can often find mistletoes. These parasitic plants are usually benefited by habitat degradation as result of large sunlight incidence and increased visitation rates of generalist mutualists (Bowen et al. 2009), but such apparent benefit involves less obvious ecological consequences such as changes in fruit traits (Fontúrbel et al. 2017a); Fontúrbel \& Medel 2017). Those changes can have important effects at the community scale, as variation in mistletoe fruit traits may also alter detection, removal and consumption probabilities by frugivores (Onstein et al. 2017), ultimately affecting plant recruitment. Here we focused on the hemiparasitic mistletoe Tristerix corymbosus (L.) Kuijt (Loranthaceae), a common species of southern South America. Previously we found that microclimatic conditions (and particularly sunlight incidence, which affects fruit ripening process) on abandoned Eucalyptus globulus Labill. plantations favored larger seeds on T. corymbosus, but there were no significant changes in fruit size (Fontúrbel \& Medel 2017). Additionally, mistletoes showed lower visitation rates at the plantation, compared to the native forest (Fontúrbel et al. 2017a). Based on this evidence, we hypothesized that forest replacement will alter $T$. corymbosus fruit shape as result of differences in microclimatic conditions. To test this hypothesis, we used a geometric morphometric approach.

This study was conducted at the Valdivian Coastal Reserve $\left(39^{\circ} 57^{\prime} \mathrm{S} 73^{\circ} 34^{\prime} \mathrm{W}\right)$, a 50,000 -ha private protected area, managed by The Nature Conservancy (Delgado 2010). This private reserve protects an important fraction of the Valdivian rainforest, ecosystem considered as a biodiversity hotspot due to its high proportion of endemic species (Mittermier $e t$ al. 2005). This Reserve comprises a complex habitat mosaic that consists of native forest and abandoned Eucalyptus globulus plantations. The native forest is dominated by Nothofagus nitida (Phil.) Krasser, N. pumilio (Poepp. \& Endl.) Krasser, Fitzroya cupressoides I.M.Johnst., Laurelia philippiana Looser, Lomatia ferruginea (Cav.) R.Br., and Mitraria coccinea Cav.; whereas the abandoned plantation is dominated by the exotic tree Eucalyptus globulus, plus many understory native plants, being Rhaphithamnus spinosus (Juss.) Moldenke, Aristotelia chilensis (Molina) Stuntz, Lapageria rosea Ruiz \& Pav. and Chusquea quila Desvau the most abundant ones (Fontúrbel et al. 2015). We found $T$. corymbosus in both habitats, parasitizing different 
native host species (Fontúrbel et al. 2017b), but not $E$. globulus. At the temperate rainforests of southern South America (i.e., southwards $37^{\circ} \mathrm{S}$ ) T. corymbosus is solely dispersed by Dromiciops gliroides, a frugivorous arboreal marsupial (Amico \& Aizen 2000), relying on this species to safely deposit seeds on hosts' branches. Despite frugivorous birds such as Mimus thenca (legitimate disperser of many Tristerix species) are present at the study area, a fruit color polymorphism is likely to be precluding them to consume T. corymbosus fruits at the temperate forests, as ripe fruits remain green -and therefore, undetectable by birds because of the lack of chromatic contrast- due to different sunlight exposure (Amico et al. 2011).

During the 2012-2013 austral summer, we sampled 70 adult mistletoes. We collected five ripe fruits from each mistletoe, which were photographed within $6 \mathrm{~h}$ from collection. Fruits photos were taken at the same light conditions, at a distance of $20 \mathrm{~cm}$ from a flat surface, holding camera perpendicularly. We used a Panasonic Lumix DMCFZ50 camera (Panasonic Co, Newark NJ). Also, we obtained UTM coordinates of the sampled mistletoes using a Garmin GPS Map 62s device (Garmin, Lenexa KS) with a $\leq 3 \mathrm{~m}$ error, measured the amount of light received by each plant using a handheld luxometer, and, registered the host species parasitized by each sampled mistletoe. To characterize the environment surrounding each mistletoe we quantified the proportion of native habitat in a 50-m radius, using aerial photographs and base cartography of the Valdivian Coastal Reserve, as described by Fontúrbel et al. (2015).

To examine fruit shape on the sampled mistletoes we used a geometric morphometric analysis based on contours, consisting on four sequential steps: [1] Optimize fruit pictures in order to get binary images (black fruits on a white background) to optimize shape recognition. Some fruits were excluded from the analysis due to blurry edges or unusual irregularities, resulting in a total of 61 plants and 253 fruits included in the analysis. Fruit optimization was conducted using Adobe Photoshop CS6. Fruits of the same individual were saved together in one bitmap file. [2] We used the SHAPE v1.3 (Iwata \& Ukai 2002), a software package for assess quantitatively biological shapes, based on elliptic Fourier descriptors (EFD hereafter). SHAPE is composed of four independent analysis modules. First, we used the ChainCoder module to smooth shapes, give a unique ID to fruits within individuals, and obtain the chain code based on the contours of the fruits, which necessary for the following step. Then, we used the Chain2Nef module to perform a Fourier elliptic transformation (based on the chain code generated) to obtain the EFDs. This kind of transformation is recommended for closed shapes that resemble an ellipse (Kuhl \& Giardina 1982), like T. corymbosus fruits. We used the normalization based on the first harmonic ellipse, using 20 harmonics. We aligned shapes to their larger axis, fruits were oriented to the left in all cases. [3] Once we had calculated the EFDs, we used the PrinComp module to obtain principal components from the normalized Fourier descriptors to summarize and make them easier to analysis (Rohlf \& Archie 1984). Principal components were calculated based on the variance-covariance matrices. We extracted the principal components generated altogether with their scores, necessary for conducting further statistical analyses. [4] We used the PrinPrint module to obtain a graphical visualization of the shape variation explained by each principal component.

To assess the effect of habitat replacement and luminosity of fruit shape, we used the first two principal components resulting from the geometric morphometric analysis (explaining $71.07 \%$ of the variance) as dependent variables. We fitted spatially explicit Generalized Additive Mixed Models (GAMM), using native habitat proportion, luminosity (values were standardized to mean 0 and variance 1 to avoid large estimate figures in the models) and host species as linear fixed parameters, geographic coordinates were included as a spline term (using a cubic spline smoother), and plant ID as a random factor to account for intra-individual variability (Zuur et al. 2009, Wood 2017). We used a Gaussian error distribution; models were fitted using a restricted maximum likelihood approach. We fitted GAMMs using the gamm4 package (Wood \& Scheipl 2014) in R 3.4.2 (R Development Core Team 2017). We generated seven candidate models, which were compared by AICc and BIC to select the one with largest explanatory power. Original data, $\mathrm{R}$ script, detailed multi-model selection information, and raw SHAPE outputs associated to this paper are available at the figshare repository (https:// doi.org/10.6084/m9.figshare.5830668).

We obtained 77 principal components from the EFDs of the contour analysis performed, being the first nine components significant. Those nine components explained $92.33 \%$ of the fruit shape variance. We kept the first two principal components, explaining $71.07 \%$ of the variance (PC1 60.45\% and PC2 10.62\%), to explain between-habitat shape differences. The PC1 captured the elliptical variation (rounded to elongated fruit shapes), whereas the PC2 captured the shape variance at fruit's tip (Figure 1a). From the seven candidate models fitted (details are available on the figshare repository) the model with the best explanatory power was the one including native habitat proportion only. Examining the effects of forest replacement on fruit shape, we found a significant effect of the amount of the remaining native habitat on PC1 (GAMM estimate $0.032 \pm 0.015$, $\mathrm{P}=0.030$ ) but found no effect on PC2 (GAMM estimate $-0.001 \pm 0.005, P=0.795$; Figure $1 b$ ). These results show that fruits are more rounded at the plantation (i.e., negative $\mathrm{PC} 1$ values) but elongated at the native forest (positive $\mathrm{PC} 1$ values). We found no effects of luminosity ( $P \geq 0.465)$, host species $(P \geq 0.112)$ and the spatial structure $(P \geq 0.295)$ in any case. Residual variance of the random factor (plant 


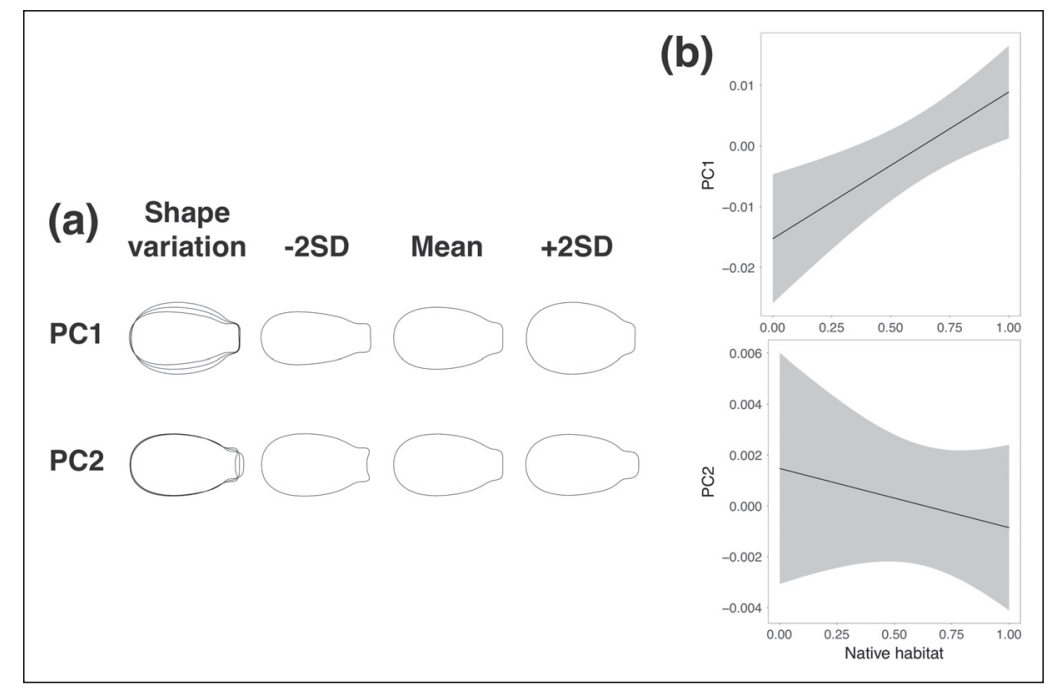

FIGURE 1. (a) Tristerix corymbosus shape variation along the first two principal components (PC1 and PC2). Mean shape \pm two standard deviations are shown. (b) Relationships between shape components (PC1 and PC2) and the proportion of native habitat (mean $\pm 95 \%$ confidence intervals are show)./ (a) Variación de la forma de Tristerix corymbosus a lo largo de los dos primeros componentes principales (PC1 y PC2). Se muestra la forma promedio \pm dos desviaciones estándar. (b) Relaciones entre los componentes de forma (PC1 y PC2) y la proporción de hábitat nativo (se muestra la media \pm el intervalo de confianza al 95\%).

ID) was $<0.001$ in all cases (detailed results are available on the figshare repository). Native habitat proportion and luminosity were not correlated (Pearson's correlation $\mathrm{r}=$ $-0.060, \mathrm{P}=0.952$ ).

We found a significant shape variation between the native forest and the abandoned E. globulus plantation. Despite $T$. corymbosus is able to persist in the habitat dominated by exotic trees, it is experiencing phenotypic changes. Previously, Fontúrbel and Medel (2017) reported larger seeds at the plantation, but no significant changes were observed in fruit size between habitats. Fruit size largely varied among mistletoes along the study area but given that contour-based geometric morphometric analysis is independent of size, it would not affect our results. Then, lower D. gliroides visitation rates were reported at the plantation, but feeding time spent on each mistletoe was up to three times larger than into the native forest (Fontúrbel et al. 2017a; 2017b). This evidence suggest that phenotypic changes caused by habitat replacement can affect other processes at the community level, such as seed dispersal, as fruit shape is an important factor determining plant-frugivore interaction, altering detection, removal and consumption probabilities (Onstein et al. 2017), which largely determine plant recruitment (Jordano 2000).

Microclimate conditions can alter fruit traits (Galetti et al. 2003). In this case, the most likely explanation to the shape variation found was light incidence as abandoned plantations are structurally simpler and have an opener canopy compared to the native forest, being E. globulus is the only species above $3 \mathrm{~m}$ (the remaining native understory vegetation is dominated by shrubs and small trees). Therefore, they are more exposed to sunlight and have warmer temperatures than the native forest (Fontúrbel \& Medel 2017). However, the lack of effect of luminosity on fruit shape variation suggests that the structural modification resulting from forest replacement would alter microclimatic conditions beyond our field measurements (evidenced by the lack of correlation between native habitat proportion and luminosity). Also, our results showed that fruit shape varied irrespectively of the host plant species parasitized, reinforcing the idea of a microclimate influence.

To sum up, the empirical evidence presented here show changes in T. corymbosus' fruit shape as result of forest replacement by exotic Eucalyptus monocultures. Further, those changes are likely to alter its relationship with the sole seed disperser, the relict marsupial D. gliroides. Based on these preliminary results, we encourage future studies aimed at examining phenotype changes in detail, as we live in a changing world where the ecological scenario is more dynamic than ever, breaking the ground for many species but also for the ecological interactions occurring among them.

\section{ACKNOWLEDGMENTS}

D.A. Salazar and J. Malebrán assisted in field. TNC and the Valdivian Coastal Reserve granted access to the field site. Rufford Foundation (14669-2) and FONDECYT project 11160152 provided funding. 


\section{REFERENCES}

Amico, G.C., Aizen, M.A. 2000. Mistletoe seed dispersal by a marsupial. Nature 408: 929-930.

Amico, G.C., Rodríguez-Cabal, M.A., Aizen, M.A. 2011. Geographic variation in fruit colour is associated with contrasting seed disperser assemblages in a south-Andean mistletoe. Ecography 34: 318-326.

Bowen, M.E., McAlpine, C.A., House, A.P.N., Smith, G.C. 2009. Agricultural landscape modification increases the abundance of an important food resource: mistletoes, birds and brigalow. Biological Conservation 142: 122-133.

BRown, C. 2001. Future production from forest plantations. Food and Agriculture Organization, Rome. 16 pp.

Chapin III, F.S., Zavaleta, E.S., Eviner, V.T., Naylor, R.L., Vitousek, P.M., Reynolds, H.L., Hooper, D.U., Lavorel, S., Sala, O.E., Hobbie, S.E., Mack, M.C., Díaz, S. 2000. Consequences of changing biodiversity. Nature 405: 234242.

Delgado, C. 2010. Plan de manejo Reserva Costera Valdiviana [Management plan of the Valdivian Coastal Reserve]. The Nature Conservancy, Arlington VA. 137 pp.

Echeverría, C., Coomes, D., Salas, J., Rey-Benayas, J.M., Lara, A., Newton, A. 2006. Rapid deforestation and fragmentation of Chilean temperate forest. Biological Conservation 130: 481-494.

Fontúrbel, F.E., Candia, A.B., Castaño-Villa, G.J. 2016. Are abandoned eucalyptus plantations avifauna-friendly? A case study in theValdivian rainforest. Revista Mexicana de Biodiversidad 87: 1402-1406.

Fontúrbel, F.E., Jordano, P., Medel, R. 2015. Scale-dependent responses of pollination and seed dispersal mutualisms in a habitat transformation scenario. Journal of Ecology 103: 1334-1343.

Fontúrbel, F.E., Jordano, P., Medel, R. 2017a. Plant-animal mutualism effectiveness in native and transformed habitats: Assessing the coupled outcomes of pollination and seed dispersal. Perspectives in Plant Ecology Evolution and Systematics 28: 87-95.

FontúRBel, F.E., Medel, R. 2017. Frugivore-mediated selection in a habitat transformation scenario. Scientific Reports 7: 45371.

Fontúrbel, F.E., Salazar, D.A., Medel, R. 2017b. Why mistletoes are more aggregated in disturbed forests? The role of differential host mortality. Forest Ecology and Management 394: 13-19.

Galetti, M., Alves-Costa, C.P., Cazetta, E. 2003. Effects of forest fragmentation, anthropogenic edges and fruit colour on the consumption of ornithocoric fruits. Biological Conservation 111: 269-273.

IwATA, H., UKaI, Y. 2002. SHAPE: A computer program package for quantitative evaluation of biological shapes based on elliptic Fourier descriptors. Journal of Heredity 93: 384385 .
Jordano, P. 2000. Fruits and frugivory. In: M. Fenner (ed.), Seeds: The Ecology of Regeneration in Plant Communities, pp. 125-166. CAB International, Wallingford.

Kinnison, M.T., Hendry, A.P., Stockwell, C.A. 2007. Contemporary evolution meets conservation biology II: Impediments to integration and application. Ecological Research 22: 947-954.

KuHL, F.P., GiardinA, C.R. 1982. Elliptic Fourier features of a closed contour. Computer Graphics and Image Processing 18: $236-258$

LomÁscolo, S.B., Schaefer, H.M. 2010. Signal convergence in fruits: a result of selection by frugivores? Journal of Evolutionary Biology 23: 614-624.

Mittermier, R.A., Gil, P.R., Hoffman, M., Pilgrim, J., Brooks, T., Mittermier, C.G., Lamoreux, J., Da Fonseca, G.A.B. 2005. Hotspots revisited: Earth's biologically richest and most threatened terrestrial regions. CEMEX, Monterrey. $392 \mathrm{pp}$.

NÁJera, A., Simonetti, J.A. 2009. Enhancing avifauna in commercial plantations. Conservation Biology 24: 319324.

Newbold, T., Hudson, L.N., Hill, et Al. 2015. Global effects of land use on local terrestrial biodiversity. Nature 520: 4550.

Onstein, R.E., Baker, W.J., Couvreur, T.L.P., Faurby, S., Svenning, J.C., Kissling, W.D. 2017. Frugivory-related traits promote speciation of tropical palms. Nature Ecology and Evolution 1: 1903-1911.

Peh, K.S.H., Sodhi, N.S., De Jong, J., Sekercioglu, C.H., Yap, C.A.M., LIM, S.L.H. 2006. Conservation value of degraded habitats for forest birds in southern Peninsular Malaysia. Diversity and Distributions 12: 572-581.

R Development Core Team. 2017. R: A language and environment for statistical computing, reference index version 3.4.2. Vienna, Austria: Foundation for Statistical Computing.

Rohlf, F.J., Archie, J.W. 1984. A comparison of Fourier methods for the description of wing shape in mosquitoes (Ritera culicidae). Systematic Zoology 33: 302-317.

Sala, O.E., Chapin, F.S., Armesto, J.J., Berlow, E., Bloomfield, J., Dirzo, R., Huber-Sanwald, E., Huenneke, L.F., Jackson, R.B., Kinzig, A., Leemans, R., Lodge, D.M., Mooney, H.A., Oesterheld, M., Poff, N.L., Sykes, M.T., Walker, B.H., Walker, M., Wall, D.H. 2000. Biodiversity Global biodiversity scenarios for the year 2100. Science 287: 1770-1774.

Stockwell, C.A., Hendry, A.P., Kinnison, M.T. 2003. Contemporary evolution meets conservation biology. Trends in Ecology and Evolution 18: 94-101.

Wood, S., ScheIPL, F. 2014. gamm4: Generalized additive mixed models using mgcv and lme4. R package version 0.2-3: http://CRAN.R-project.org/package=gamm4.

Wood, S.N. 2017. Generalized Additive Models: An introduction with R. CRC Press, Boca Raton, FL. 471 pp.

Zuur, A., Ieno, E.N., Walker, N., SAveliev, A.A., Smith, G.M. 2009. Mixed effects models and extensions in ecology with R. Springer, New York 549 pp.

Recibido: 28.01.2018

Aceptado: 14.05.2018 